\title{
Bioenrichment of Guava Juice with Prebiotic and Probiotics
}

\author{
Nausheen Saba ${ }^{1 *}$, B. Narayana Swamy ${ }^{1}$, B.S. Nalini ${ }^{1}$, G. Ashiwini ${ }^{1}$ and Priyanka Prasad ${ }^{2}$ \\ ${ }^{1}$ Department of Microbiology, University of Agricultural Sciences, Bengaluru- 560065 , \\ Karnataka, India \\ ${ }^{2}$ Department of Forestry and Environmental Sciences, University of Agricultural Sciences, \\ Bengaluru- 580 065, Karnataka, India \\ *Corresponding author
}

\section{A B S T R A C T}

\section{Keywords}

Probiotic, Prebiotic,

Saccharomyces

cereviceae,

Saccharomyces

boulardii and

Enrichment

Article Info

Accepted:

10 June 2018

Available Online:

10 July 2018
Four different yeast strains viz., Saccharomyces cereviceae-1, Saccharomyces cereviceae-2, Saccharomyces boulardii, isolate SYG were evaluated for the fermentation of guava juice (cv. Allahabad safeda) for nutrient enrichment. Guava juice blended with honey and fermentation by different yeasts studied for bio enrichment of guava juice. The results revealed that the guava juice blended with honey as prebiotic and fermented by probiotics of yeast Saccharomyces boulardii showed enriched nutritional contents with respect to TSS $\left(7.70^{\circ} \mathrm{Brix}\right), \mathrm{pH}(3.04)$, acidity $(1.26 \%)$, alcohol $(3.40 \%)$, and yeast counts $\left(10.02 \mathrm{cfu} \times 10^{7} / \mathrm{ml}\right)$ organolyptic score (17.25) when compared to other treatments. The results concluded that the combined fermentation of guava juice blended with 4 per cent honey could be bio enriched product from guava juice and it will be new product in the food industry.

\section{Introduction}

Guava belongs to the family Myrtaceae and it is native to tropical America (Neotropics), it is cultivated in all tropical and subtropical countries and thus one of the important fruit crops of India (Chopda and Barrett, 2001; Ghosh et al., 2013). It is also known as 'Poor man's apple of tropics' (Kamath et al., 2008). Guava has been in cultivation in India since 17 th century and gradually became the crop of commercial significance and also common fruit tree in the backyard of houses in India. Guava is a fair source of minerals and vitamins like vitamin A (250 IU per $100 \mathrm{~g}$ of pulp), Ascorbic acid (75-265 mg per $100 \mathrm{~g}$ of pulp), thiamin, riboflavin and niacin and phosphorus (17.8-30 mg per 100g of pulp) (Ghosh and Chattopadhyay, 1996 and Das et al., 1995).

Harvesting of guava is done from mid-October to the end of January in the Malwa region of Madhya Pradesh. Guava is a seasonal fruit and 
it is normally consumed fresh as dessert fruit that is pleasantly sweet and refreshing in flavour. Short storage life (6-8 days) limits strategic selling of fresh guava fruit. Under these conditions guava growers fail to get attractive returns and nearly 20-25 per cent of produce goes as ravage (Nidhi and Prasad 2006).

Various processed products are made from guava viz. jam, jelly, cheese, canned fruit segments, ready to serve drink, nectar, squash, dried powder, ice cream, highly concentrated puree, candy, toffees, syrup, juice and concentrate (Jain and Asati, 2004), thereby minimizing the postharvest losses, enhances its economic and nutritive values.

Guava wine is the product of anaerobic fermentation by yeast in which the sugars are converted into alcohol and carbon dioxide (Anderson et al.2005).Fermented guava beverage is the product of anaerobic fermentation by yeast in which the sugars are converted into alcohol and carbon dioxide. Fermented guava beverage production from guava pulp or juice is reported by Gurvinder $e t$ al., (2011).

There are several reports on alcoholic beverages from different fruits like apple, plum, apricot, pomegranate, strawberry, guava, jamun, sapota, litchi, amla, orange, carambola etc. (Sandhu and Johi 1995; Joshi and Sharma, 1994; Adusule et al., 1992; Joshi et al., 2005 and Zeng et al., 2008). Traditionally, fermentation of fruit juice was carried by wild yeast. However, with the advancement in the field of genetic engineering, genetically modified strains Saccharomyces cereviceae are currently being used for the production of fermented beverages.

The quality of fermented beverage is depending upon a number of factors like cultivars, adequate sugar level, acid content, colour, aroma and strains used (Ethiraj and Suresh, 1993).

Probiotics are food supplements containing beneficial microorganisms.

The main intention to prepare this probiotic drink is to assist in reviving the body's naturally own micro-flora within the digestive tract to re-establish themselves. Some of the medicinal importance of the probiotics are: prevention of colon cancer, reducing the cholesterol, reducing inflammation, improving assimilation and absorption as well as managing lactose tolerance (Dipjyoti et al, 2015).

Prebiotics were originally defined as 'nondigestible food ingredients that beneficially affect the host by selectively stimulating the growth and/or activity of one or a limited number of microorganism species already resident in the colon, and thus attempt to improve host health' (Gibson and Roberfroid, 1995).

Honey with fruits and vegetables gained lot of importance with respect to nutritional and health point since, honey is very rich in sugar and many medicinal properties, four per cent of honey is blended to guava juice in the present study.

Keeping in view the above facts, the present study was undertaken to produce good quality fermented guava beverage, with the following objectives.

\section{Materials and Methods}

The proven and authenticated yeast cultures were procured from Microbial Type Culture Collection Center (MTCC), Chandigarh, India in the form of lyophilized cultures. This proven strains along with the isolates obtained 
from natural sources where used in the fermentation studies.

\section{Isolation of yeast from guava fruits}

Isolate of yeast (SYG) were isolated from guava fruit by following standard procedure. The native isolated yeast from guava fruits were labelled as SYG. The pure culture of yeast were obtained in the form offreeze dried ampoules and these cultures were revived using YEPDA for yeast and maintained in the form of agar slant cultures for further use.

Preparation of guava juice (Hossen et al., 2009)

Guava juice was prepared as per the procedure outlined by Hossen et al., (2009). Healthy guava fruits (cv Allahabad safeda) were procured from market and washed in water and cut the fruit into pieces blended the fruit into pulp using kitchen blender, water, sugar, citric acid (2.2 g/l) and preservative (sodium benzoate- 2 gms) were added. Sugar was added to attain the required TSS. Pasteurization was done at $85^{\circ} \mathrm{C}$ for $2-3$ minutes. Flow chart for the preparation of guava juice.

Flow chart for the preparation of guava juice

Healthy guava fruit<smiles>[CH]</smiles>

Wash with water to remove dust<smiles>[CH]</smiles>

Cutting fruit into quarters<smiles>[Tl]</smiles>

Blending the fruit into pulp

I

Filtration (Removal of seeds) ת

Pulp boiling (Temp-85 0C for 3 mins)

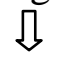

Adding water, citric acid $(2.2 \mathrm{~g} / \mathrm{l})$, preservative (sodium benzoate-2 $\mathrm{g} / \mathrm{l}$ )
ת

Addition of sugar to adjust the TSS (150 Brix)

I]

Pasteurization at $80 \mathrm{oC}$ for $2-3$ minutes

ת

Cooling and Filtration

Storage

\section{Preparation of yeast starter culture}

Loop full of inoculum of different strains of yeast culture were transferred to conical flasks containing $100 \mathrm{ml}$ of YEPDA broth. The inoculated flasks were kept for 2-3 days' incubation at $28{ }^{\circ} \mathrm{C}$. These broth cultures of yeast cultures were inoculated with an initial population of $107 \mathrm{cfu} / \mathrm{ml} @ 5$ per cent to 300 $\mathrm{ml}$ guava juice in a $500 \mathrm{ml}$ conical flask for fermentation.

\section{Microbiological and biochemical analysis pH}

The $\mathrm{pH}$ of the guava juice samples was determined using a digital $\mathrm{pH}$ meter (YORCO pH meter, model: YSI - 601). The $\mathrm{pH}$ meter was standardised with buffer solutions of different $\mathrm{pH}(4.0,7.0,10.0)$ were used to calibrate the instrument. Each sample was replicated three times and its mean value was taken as $\mathrm{pH}$ of the sample (Sadasivam and Manickam, 1996).

\section{Titrable acidity (Srivastava and Kumar, 1993)}

Fresh filtered homogenised pulp $10 \mathrm{~g}$ was made up to $100 \mathrm{ml}$ with distilled water. From this $10 \mathrm{ml}$ of the prepared solution was titrated against $\quad 0.1 \mathrm{~N} \quad \mathrm{NaOH}$ solution using phenolphthalein as indicator. The appearance of a light pink colour was the end-point that quantifies the $\mathrm{NaOH}$ required to neutralise the juice. Then the titrable acidity was calculated and expressed as per cent citric acid 
(Ranganna, 1995). Amount of titrable acidity present in $100 \mathrm{~g}$ of sample was calculated as follows.

Titrable acidity $(\%)=$

Titre value $\times \mathrm{N}$ of $\mathrm{NaOH} \times$ Equivalent Wt. of acid $\times 100$

Volume of sample taken $\times$ Weight of the sample $\times 1000$

\section{Total soluble solids}

Total soluble solid (TSS) was measured using a hand refractometer. Samples were crushed and made into juice. One or two drops of juice were placed on the hand refractometer for TSS measurement. It was expressed in degree Brix (Ranganna, 1995).

\section{Estimation of reducing sugars (Sadasivam and Manickam, 1996)}

The reducing sugars were estimated by following the method as given by ShafferSomagyi micro method.

\section{Estimation of alcohol (Distillation method)}

Alcohol was estimated calorimetrically as described by Caputi et al. (1968)

\section{Organoleptic evaluation}

The developed fermented beverage from blended guava juices were evaluated by selected 5 panel members with 20 point hedonic scales (Amerine et al., 1972) was taken into consideration, which was based mainly on the appearance, colour, aroma, taste and acceptability.

\section{Sample preparation for organoleptic evaluation}

Each sample was coded prior to testing and placed in a random manner, the different samples were placed along with glass of water (to rinse the mouth) in the laboratory and panellists were instrument to evaluate each sample by tasting as per the scorecard.

\section{Microbiological analysis of yeast}

After 7 days of fermentation, the samples were subjected for microbiological analysis of yeast counts by employing standard dilution plate count method (Hoben and Somasegaran, 1982).

$10 \mathrm{ml}$ of sample was diluted in $90 \mathrm{ml}$ water blank (10-1) then subsequent dilutions were made up to $10-4$ dilution. $1 \mathrm{ml} 103$ and 104 dilutions of were used for plating. YEPDA media were poured into the Petri dishes containing respective dilutions of the different samples and rotate the media poured plates both clock and anti-clock wise direction for uniform mixing of the sample. And allowed to solidify, later kept for incubation at $28-30^{\circ} \mathrm{C}$ for yeast.

\section{Blending material}

\section{Honey}

Four per cent of honey was used as prebiotic and blended to the guava juice wherever it is required in the treatments. The experiment was conducted to known the combined effect of probiotics and prebiotic of yeast for the fermentation of blended guava juice for nutrient enrichment. The treatment details are as follows.

\section{Experimental Treatments}

$\mathrm{T} 1=$ Control (Guava juice)

$\mathrm{T} 2$ = Guava juice + yeast (Saccharomyces boulardii)

$\mathrm{T} 3$ =Guava juice +4 percent honey + yeast (Saccharomyces boulardii)

$\mathrm{T} 4$ = Guava juice + yeast (Saccharomyces cerevisiae-1)

$\mathrm{T} 5$ =Guava juice +4 percent honey + yeast 
(Saccharomyces cerevisiae-1)

T6 = Guava juice + yeast (Saccharomyces cerevisiae-2)

$\mathrm{T} 7$ =Guava juice +4 percent honey + yeast(Saccharomyces cerevisiae-2)

T8 $=$ Guava juice + yeast SYG (guava isolate)

$\mathrm{T} 9=$ Guava juice +4 percent honey + yeast SYG (guava isolate)

\section{Replications}

3, Fermentation period: 7 days' fermentation

The broth cultures of yeast strains containing $107 \mathrm{cfu} / \mathrm{ml}$ were inoculated to the respective treatments. The inoculated flasks and control flasks were plugged with rubber cork with bent tube and kept for fermentation for 7 days under room temperature $\left(27-28^{0} \mathrm{C}\right)$. After 7 days of fermentation the fermented juice was filtered through muslin cloth and the filtrate was kept in sterilized glass bottles.

The filtrate fermented juice was subjected for biochemical and microbiological analysis by following standard procedures as mentioned in the section.

\section{Results and Discussion}

The experimental results pertaining to the effect of yeast for the efficiency of fermentation of blended guava juice with honey, organoleptic evaluation of the fermented beverages from different treatments for the duration of synbiotic fermented guava beverages are presented in this chapter.

\section{Details of different yeasts}

Yeast spp were isolated from different natural sources (SYG), Saccharomyces boulardii, Saccharomyces cerevisiae-1 and Saccharomyces cerevisiae-2. The cultures obtained were added to enrichment media and they were cultured by standard dilution plate count method and they were sub cultured on sterile petri plates containing solidified sterile YEPD medium under aseptic condition and cultures were preserved for further studies and isolated yeast cultures were named based on the sources of isolation.

\section{Effect of yeast for the fermentation of guava juice blended with honey}

The experiment was conducted to know the efficiency of different yeast strains for the fermentation of guava juice. The results pertaining to $\mathrm{pH}$, TSS, titrable acidity, reducing sugars., non reducing sugars and alcohol content of fermented guava juice by the influence of different yeast strains are presented in table-1.

\section{pH, TSS (Brixo) and Titrable acidity (\%)}

The initial $\mathrm{pH}$ of the guava juice was 3.50 (initial value). After 7 days of fermentation by different yeast strains, the change in $\mathrm{pH}$ of the fermented guava juice varied between 02.96 to 03.20. The guava juice fermented by yeast strain Saccharomyces cerevisiae -1 without blending with honey recorded lowest $\mathrm{pH}$ (02.90) followed by strains Saccharomyces boulardii without blending with honey and SYG (guava isolate) with blending with honey had the same effect on $\mathrm{pH}$ (2.92) . Saccharomyces cerevisiae -2 did not much influence (3.20) change of $\mathrm{pH}$ in the fermented guava juice. The $\mathrm{pH}$ of the fermented beverage depends upon the acids and sugar contents of juice. Similar results were reported by Nguyen Phuoc Minh (2014) in guava juice fermented by yeast were chemical characteristics for samples at 4 sugar contents: 150Bx, 170Bx, 190Bx, 210Bx; and $\mathrm{pH}=3.5$, these content increases to $210 \mathrm{Bx}$, $\mathrm{pH}$ decreases slightly. Yeast fermentation of guava juice with and without blending showed more decreased in $\mathrm{pH}$. Similarly, Priya et al., 2010 reported that tomato juice fermentation 
by yeast Saccharomyces cerevisiae 3283 strain results in reduction of $\mathrm{pH}$ from 4.4 to 3.1 .

The initial TSS of the guava juice was $15^{\circ}$ brix. After 7 days of fermentation, it was observed that the TSS content varied from $15^{\circ}-4.63^{\circ}$ brix between strains. The TSS content was $4.63^{\circ}$ brix in juice fermented by strain Saccharomyces cerevisiae -2 followed by the isolate yeast (guava isolate) ( $\mathrm{SYG}$ ) $5.13^{\circ}$ brix. The results have indicated that the yeast strain Saccharomyces cerevisiae -2 utilized more sugar during the period of 7 days of fermentation followed by yeast-(guava isolate) (SYG). Nguyen Phuoc Minh (2014) showed similar results with yeast.

The initial titrable acidity of the guava juice was 0.78 per cent. After 7 days of fermentation, it was observed that the titrable acidity increased by the influence of different strains of yeast. Among yeast isolate, the highest titrable acidity $(1.40 \%)$ was obtained in the juice fermented by SYG isolate and lowest was $(0.50 \%)$ was observed with the case of strain Saccharomyces cerevisiae-2. Similar results were reported in jamun wine by Chowdhury and Ray, (2007) by yeast fermentation.

\section{Alcohol (\%), reducing sugar (\%) and non reducing sugar $(\%)$}

Alcohol production ranges from 00.00 to 3.40 $\%$ between the strains of yeast. However, highest percentage of alcohol (5.05\%) was produced in the guava juice fermented by Saccharomyces cerevisiae -2 . The least alcohol content of (3.40) Saccharomyces boulardii and SYG yeast (guava isolate) was observed in the juice fermented guava juice which are significantly differ with respect to alcohol content between yeast strains. Similar report has been published by Wahab $\mathrm{O}$ kunowo et al. (2005) in their study of alcoholic fermentative efficiency of indigenous yeast strains on orange juice and reported that the highest alcohol produced by Saccharomyces carlsbergensis (6,8 percent) and least was produced by Saccharomyces cerevisiae (3.19 per cent) also confirmed with the results of Chaudhari and Chincholkar (1996) who reported that among 30 yeast strains; a strain was able to ferment 15 percent of total sugars in molasses to ethanol $(51 \mathrm{~g} / \mathrm{l})$.

The results revealed that the initial value of reducing sugar in the guava juice was 3.99 per cent. After 7 days of fermentation, the reducing sugar level varied from 3.99 to 1.90 per cent between yeast strains. Among yeast strains, the lowest reducing sugars $(1.90 \%)$ was observed in the juice fermented by yeast strains blended with honey indicating more utilization of sugar during fermentation.

The initial value of non-reducing sugar in the juice was $1.56 \%$. After 7 days of fermentation, variation in non reducing sugar level were observed between yeast strains. The non-reducing sugar levels varied from 4.25 to $6.06 \%$ between the yeast strains. The highest non reducing sugar level $(1.95 \%)$ was observed in the juice fermented by yeast Saccharomyces boulardii blended with honey.

\section{Population of yeast counts in the fermented guava beverages}

The yeast population was analyzed in the guava juice fermented by different strains of yeast after 7 days of fermentation. The initial inoculum of different yeast strains was added to the guava juice at $107 \mathrm{cfu} / \mathrm{ml}$ to the guava juice. After 7 days of fermentation, the highest population of yeast strains was $10.02 \mathrm{X}$ $107 \mathrm{cfu} / \mathrm{ml}$ by Saccharomyces boulardii blended with honey and the least was 8 X 107 $\mathrm{cfu} / \mathrm{ml}$ by SYG isolate, Saccharomyces cerevisia-1 and Saccharomyces cerevisiae-2 without blending with honey. 
Table.1 Influence of yeast fermentation on different biochemical analysis of guava juice

\begin{tabular}{|c|c|c|c|c|c|c|c|c|c|c|}
\hline \multirow[t]{2}{*}{ Sl.no } & \multirow[t]{2}{*}{ Treatments } & \multirow[t]{2}{*}{$\mathrm{pH}$} & \multirow{2}{*}{$\begin{array}{l}\text { TSS } \\
\left(\text { Brix }^{0}\right)\end{array}$} & \multirow{2}{*}{$\begin{array}{c}\text { Titrable } \\
\text { acidity }(\%)\end{array}$} & \multirow{2}{*}{$\begin{array}{l}\text { Reducing } \\
\text { sugar (\%) }\end{array}$} & \multirow{2}{*}{$\begin{array}{l}\text { Non-reducing } \\
\text { sugar }(\%)\end{array}$} & \multirow[t]{2}{*}{ Alcohol (\%) } & \multicolumn{3}{|c|}{$\begin{array}{c}\text { Population } \\
\text { Yeast cfu X } 10^{7} / \mathrm{ml}\end{array}$} \\
\hline & & & & & & & & $7^{\text {th }}$ day & $30^{\text {th }}$ day & $45^{\text {th }}$ day \\
\hline 1. & $\mathrm{~T}^{1}$ & 3.50 & 15.00 & 0.78 & 3.99 & 1.56 & 00.00 & 00.00 & 00.00 & 00.00 \\
\hline 2. & $\mathrm{~T}^{2}$ & 2.92 & 6.01 & 1.26 & 2.45 & 1.55 & 4.45 & 8.04 & 10.20 & 4.50 \\
\hline 3. & $\mathrm{~T}^{3}$ & 3.04 & 7.70 & 1.26 & 1.90 & 1.95 & 3.40 & 10.02 & 11.20 & 5.50 \\
\hline 4. & $\mathrm{~T}^{4}$ & 2.90 & 6.30 & 0.50 & 2.44 & 1.45 & 5.00 & 8.00 & 10.30 & 4.00 \\
\hline 5. & $\mathrm{~T}^{5}$ & 3.00 & 7.40 & 0.60 & 1.90 & 1.65 & 4.65 & 10.00 & 11.30 & 5.50 \\
\hline 6. & $\mathrm{~T}^{6}$ & 3.02 & 4.63 & 1.28 & 2.12 & 1.48 & 5.05 & 8.00 & 10.30 & 4.20 \\
\hline 7. & $\mathrm{~T}^{7}$ & 3.20 & 7.30 & 1.32 & 1.90 & 1.73 & 4.60 & 9.90 & 11.30 & 5.20 \\
\hline 8. & $T^{8}$ & 3.06 & 5.13 & 1.32 & 2.44 & 1.38 & 4.40 & 8.00 & 10.20 & 4.20 \\
\hline 9. & $\mathrm{~T}^{9}$ & 2.92 & 7.63 & 1.40 & 1.90 & 1.63 & 3.40 & 10.00 & 11.30 & 5.20 \\
\hline
\end{tabular}

Table.2 Organoleptic evaluation score of the fermented guava beverage as influenced by different yeast strains

\begin{tabular}{|c|c|c|c|c|c|c|c|c|c|c|c|}
\hline Sl.no & Treatments & $\begin{array}{c}\text { Appearance } \\
\text { (3) }\end{array}$ & $\begin{array}{l}\text { Aroma } \\
\text { (2) }\end{array}$ & $\begin{array}{l}\text { Sweetness } \\
\text { (2) }\end{array}$ & $\begin{array}{l}\text { Colour } \\
\text { (2) }\end{array}$ & $\begin{array}{l}\text { Body } \\
\text { (2) }\end{array}$ & $\begin{array}{l}\text { Flavour } \\
\text { (2) }\end{array}$ & $\begin{array}{l}\text { Vinegar } \\
\text { (2) }\end{array}$ & $\begin{array}{c}\text { Astringency } \\
\text { (2) }\end{array}$ & $\begin{array}{c}\text { General } \\
\text { quality (3) }\end{array}$ & $\begin{array}{c}\text { Overall } \\
\text { acceptability }\end{array}$ \\
\hline 1. & $\mathrm{~T}^{1}$ & 2.50 & 2.50 & 1.50 & 2.00 & 1.00 & 2.00 & 0.50 & 0.50 & 1.50 & 14.00 \\
\hline 2. & $\mathrm{~T}^{2}$ & 2.50 & 2.50 & 1.50 & 2.00 & 1.50 & 2.00 & 0.50 & 0,50 & 2.00 & 15.00 \\
\hline 3. & $\mathrm{~T}^{3}$ & 2.50 & 2.50 & 2.00 & 2.00 & 1.75 & 2.00 & 1.00 & 1.00 & 2.50 & 17.25 \\
\hline 4. & $\mathrm{~T}^{4}$ & 2.50 & 2.50 & 2.00 & 2.00 & 1.00 & 2.00 & 1.00 & 1.00 & 2.50 & 16.50 \\
\hline 5. & $\mathrm{~T}^{5}$ & 2.50 & 2.50 & 1.50 & 2.00 & 1.50 & 2.00 & 0.50 & 0.50 & 1.50 & 15.00 \\
\hline 6. & $\mathrm{~T}^{6}$ & 2.50 & 2.50 & 2.00 & 2.00 & 1.00 & 2.00 & 0.50 & 1.00 & 2.50 & 16.00 \\
\hline 7. & $\mathrm{~T}^{7}$ & 2.50 & 2.50 & 1.50 & 2.00 & 1.25 & 2.00 & 0.50 & 0.50 & 1.50 & 14.25 \\
\hline 8. & $\mathrm{~T}^{8}$ & 2.50 & 2.50 & 2.00 & 2.00 & 1.00 & 2.00 & 1.00 & 1.00 & 2.50 & 16.50 \\
\hline
\end{tabular}


Organoleptic evaluation score of the fermented guava beverage as influenced by different yeast strains

Appearance, colour, aroma, vinegar, sweetness, body, flavour, astringency, general quality and overall acceptability

Sensory evaluation was carried out for the fermented guava juice beverage by different yeast strains by a panel of 10 judges and data on organoleptic evaluation are presented in table- 2 .

The experimental results showed that the guava juice inoculated with yeast strain Saccharomyces boulardii blended with honey recorded the highest score of (17.25) respectively this indicated that the guava juice fermented by (T3) were acceptable for consumption (14 to 20).

The conclusion of the study are as follows

- Guava is a highly nutritious fruit with rich content of vitamin C. It imparts a strong aroma, flavour and a pleasant taste.

- The yeast strain Saccharomyces boulardii performed better for fermentation of guava juice with respect to enhancement of nutrients.

- Blending of 4 per cent honey favours the activity of yeast during fermentation.

- The developed products were excellent in taste, rich in nutritional quality, retained original fruit flavour and safe for consumption.

- Microbial processing of guava juice into alcoholic/ non-alcoholic fermented beverages can minimize the extent of postharvest losses in guava during glut season.

- Therefore, manufacturing of such products will provide ample avenues for employment generation in the rural masses by way of setting small scale processing unit.

\section{References}

Adusule, R. N., Kotecha, P. M. and KADAM, S. S., 1992 Preparation of wine from pomegranate. Beverage and Food World., 18: 13-14.

Anderson, C. and Badrie, N., 2005 Physicochemical quality and consumer acceptance of guava wines. J of Foo Sci Tec-Mysore., 42(3): 223-225.

Chaudary, A. B. and Chincholkar, S. B., 1996, new osmotolerant Schizosaccharomyces for ethanol production. J. Food. Sci. Technol., 36: 166-169.

Chopda, C. A. and Barrett, D. M., 2001 Optimization of guava juice and powder production. J. Food Process., 25: 41117.

Chowdhury, P. and Ray, R. C., 2007 Fermentation of jamun (Syzgium cumini L.) fruits to form red wine. Asean Food J., 14 (1): 15-23.

Das, B. S., Chakraborty, A., Chakraborty, P. K., Maiti, A., Mandal, S. and Ghosh, S., 1995 Comparative performance of guava cultivars under red and laterite soils of West Bengal. The Hort. J., 8: 141-46.

Dipjyoti, C., Sourangshu, C. and Mohanasrinivasan, $\quad$ V., 2015, Fermentation of Psidiumguajava Juice by Using Probiotic Lactic Acid Bacteria Lactobacillus Plantarum. J Nutr Food Sci., 5: 398.

Ethiraj, S. and Suresh, E. R., 1993 Fruits Wines. Advances in Horticulture., 4: 1957-1966.

Ghosh, S. N. and Chattopadhyay, N., 1996 Performance of some guava cultivar under rainfed semi-arid region of West Bengal. The Hort. J., 9: 121- 27.

Ghosh, S. N., Roy, S. and Bera, B., 2013 Study on performance of twenty-one guava cultivars in red and laterite soil of West Bengal under irrigated condition. J. Crop Weed., 9: 81-83.

Gibson, G. R. and Roberfroid, M. R., 1995 Dietary modulation of the human 
colonic microbial: introducing the concept of prebiotics. J. Nutr., 125: 1401-12.

Gurvinder Singh Kocher and Pooja., 2011

Status of wine production from guava (Psidium guajavaL.): A traditional fruit of India. J. Food Sci., 5(16): 851-860.

Hoben, H. J. and Somasegaran, P., 1982, composition of the pour, spread and drop plate methods for enumeration of Rhizobium spp. In inoculants made from pre-sterilized peat. Appl..Environ. microbiol., 14(5): 1246-1247.

Hossen, S., Kabir, M. S., Uddin, M. B., Rahman, A. K. M. L. and Mamun, M. R. A., 2009, Effect of different extractions of juice on quality and acceptability of guava jelly. J. innov. dev. strategy., 3(4): 27-35.

Jain, P. K. and Asati V. K., 2004, Evaluation of guava cultivars for pulp preparation. J. Food Sci. Technol., 41: 684-86.

Joshi, V. K. and Sharma S. K., 1994, Effect of method of must preparation and initial sugar levels on quality of apricot wine, Res Ind., 39(12): 255-257.

Joshi, V. K., Sharma S., and Bhushan S., 2005, Effect of method of preparation and cultivar on the quality of strawberry wine. Acta Alimentaria., 34(4): 339-353.

Kamath, J.V., Rahul, N., Kumar, A.C.K. and LAKSHMI, S.M. 2008. Psidium guajava L .: A Review Int. J. Green Pharm., 2: 912.

Nguyen Phuoc Minh., 2014, Investigation of

\section{How to cite this article:}

Nausheen Saba, B. Narayana Swamy, B.S. Nalini, G. Ashiwini, Priyanka Prasad. 2018. Bioenrichment of Guava Juice with Prebiotic and Probiotics. Int.J.Curr.Microbiol.App.Sci. 7(07): 1307-1315. doi: https://doi.org/10.20546/ijcmas.2018.707.156 various factors influence to fermented guava beverage production. Int $\mathrm{J}$ of Multidisciplinary Research and Development., 1(3): 125-136.

Nidhi, C. and Prasad, M., 2006, Development of guava candies. J. Food Sci. Technol., 43: $210-212$.

Ranganna., 1995, Hand book of analysis and quality control for fruit and vegetables products (2nd Ed). Tata Mc Graw Hill publishing Co, Ltd, New Delhi.

Sadasivam, S. and A. Manickam., 1996, Biochemical methods. Second Edition, New Age International (P) Limited, Publishers.

Sandhu, D. K. and Joshi, V. K., 1995, Technology, quality and scope of fruit wines especially apple beverages, Indian Food Ind., 11(1): 24-34.

Srivastava, R. P., and Kumar, S., 1993, Important methods for analysis of fruits / vegetable and their products. Fruit and Vegetable preservation principles and practices., 2nd ed. 321-229.

Wahab O., Okunowo., Rufus O., Okotore, Akinniyi, A. and Osuntoki., 2005, The alcoholic fermentative efficiency of indigenous yeast strain of different origin on orange juice. African J. of biotechnology., 4(11): 1290-1296.

Zeng, X. A., Chen, X. D., Qin, F. G. F. and Zhang, L., 2008 Composition analysis of litchi juice and litchi wine, Int J. Food Engg., 4(4): 1-16. 